\title{
Entre inércia e apatia: tensões e relaxamentos em Nízia Figueira, sua criada, de Mário de Andrade
}

\author{
Between inertia and apathy: tensions and relaxations \\ in Nízia Figueira, sua criada, by Mário de Andrade
}

Fernando de Moraes Gebra*

Resumo: O presente artigo centra-se no conto "Nízia Figueira, sua criada", de Mário de Andrade (1893-1945), Diferente das demais narrativas, em que as personagens adquirem experiência e maturidade sexual e passam de um estado de felicidade para o de infelicidade, Nízia vive uma existência inautêntica, ao permanecer em um estado de inércia, imobilismo e apatia diante das transformações sociais, políticas e econômicas que configuram a cidade de São Paulo da década de 1920. Sigmund Freud relaciona a pulsão de vida com a infelicidade, a busca incessante de satisfação. Por outro lado, a pulsão de morte equivale à felicidade, advinda da satisfação repentina de necessidades primárias do sujeito. No caso do conto em análise, há uma permanência da protagonista em um estado miticamente pré-social, anterior à alteridade. Nízia permanece limitada a uma redoma, representada pelo espaço da chácara onde vive com a criada, a quem chama de prima. O modelo semiótico da tensividade, proposto por Claude Zilberberg e divulgado no Brasil por Luiz Tatit, permite a descrição dos estados de tensão (ou pulsão de vida) e relaxamento (ou pulsão de morte) na passagem do não saber para o saber, responsável pela construção das identidades sexuais das personagens. Nessa perspectiva, o presente artigo propõe uma análise semiótica das categorias discursivas (pessoa, tempo e espaço), no quadro das modalidades tensivas, em articulação com os conceitos psicanalíticos de pulsão de vida e pulsão de morte.

Palavras-chave: Mário de Andrade. Alteridade. Modalidades tensivas. Pulsões. Duplo.

Abstract: The present paper focuses on the short-story "Nízia Figueira, sua criada", by Mário de Andrade (1893-1945). Differently from the other short-stories, in which the characters acquire experience and sexual maturity and pass from a happiness stage to an unhappiness one, Nízia has an unauthentic existence, because she continues in a slumber contrasted to the social, political and economical changes happened in São Paulo in the twenties. Sigmund Freud refers life instinct to unhappiness, the nonstop search of satisfaction. On the other hand, the death instinct equals to happiness, that comes from a suddenly satisfaction of human being's primary needs. In the short-story analyzed, the main character lives in a mythically pre-social stage that comes before the alterity. Nízia continues limited to a glass shade, represented by the croft where she lives with a handmaid to whom she calls cousin. The tensive semiotics model, proposed by Claude Zilberberg and publicized in Brazil by Luiz Tatit, allows the description of the tension (or life instinct) and relaxation (or death instinct) in the passage from the no-knowledge to the knowledge, responsible to the characters' sexual identity construction. Therefore, the present paper proposes a semiotics analysis of the discursive categories (people, time and space), in the board of tensive modalities, in articulation the psychoanalytical concepts of life instinct and death instinct.

Keywords: Mário de Andrade. Alterity. Tensive modalities. Instincts. Double

\footnotetext{
* Fernando de Moraes Gebra, Prof. Dr. Universidade Federal da Integração Latino-Americana (UNILA) e coordenador dos projetos: Poéticas da modernidade: o duplo em narrativas de língua portuguesa e espanhola do século XX; e Cinescrevendo: o cinema e as práticas identitárias. E-mail: <fernandogebra@yahoo.fr $>$
} 
Uma das preocupações centrais de Mário de Andrade (1893-1945) em seu projeto estético-ideológico refere-se à construção da identidade. O conjunto de narrativas intitulado Os contos de Belazarte aponta para a problemática das identidades individuais e sexuais, como foi visto em minha tese de doutorado Identidades intersubjetivas em contos de Mário de Andrade, além de enfatizar a descrição dos bairros operários de São Paulo e a concomitante denúncia e compadecimento do narrador Belazarte em relação ao imobilismo, ao desenraizamento, à inercia e à apatia das personagens "sem letras nem cidade". $\mathrm{O}$ foco narrativo desdobra-se, pois há o narrador Belazarte que conta suas histórias a um narrador que não é nomeado e do qual somente sabemos que trabalha como professor de música no centro de São Paulo: "Você é músico, e do conservatório grande lá da avenida S. João, por isso há-de se divertir com o caso..." (s/d., p.53). Esse narrador inominado enuncia as histórias por meio da fórmula "Belazarte me contou".

O conto "Nízia Figueira, sua criada" tem como protagonista uma personagem marcada pela "inocência primeira, anterior a todo conhecimento" de que nos fala Alfredo Bosi em estudo sobre o conto e intitulado "Intimidade e assimetria" (1996). O autor utiliza o viés sociológico para analisar as personagens Nízia (a patroa branca) e Rufina (a empregada negra), do conto em questão, afirmando que "o que a classe e a cor separam, o sentimento pode juntar". Embora rejeite as propostas estruturalistas (uma das matrizes teóricas da minha tese), a abordagem de Bosi, ainda que se trate de uma curta resenha crítica publicada em jornal, apresenta grandes contribuições para meu estudo, por se tratar de uma visada crítica a vários aspectos da relação entre Nízia e Rufina. Além disso, há nessa resenha uma afirmação que corrobora a minha proposta de trabalho de unificação temática nos contos de Mário de Andrade: "Os contos de Belazarte são histórias do encontro de experiência e infelicidade. Mário não abandonará jamais esse tema, e mais do que tema, núcleo existencial e fonte de todo o seu pathos" (1996).

$\mathrm{Na}$ contística de Mário de Andrade, se uma determinada personagem adquire experiência, esta lhe traz conflitos, causando infelicidade. No caso específico de "Nízia Figueira, sua criada", o fecho "Nízia era muito feliz" nos obriga a retomar criticamente esses contos, como um processo de construção das identidades intersubjetivas, em que cada personagem entra em disjunção com o valor "pureza" e fica conjunta com o valor "impureza". Perder a pureza 
seria a aquisição do valor "conhecimento", do "saber as coisas", expressão reiterativa no universo ficcional de Mário de Andrade. Mas Nízia nem sequer passa a "saber as coisas". Por isso seria feliz?

É importante ainda ressaltar o sentido do "saber as coisas" no que se refere à construção das identidades intersubjetivas nos contos de Mário de Andrade. Essa expressão aparece com frequência em algumas de suas narrativas, designando o processo de construção da identidade e/ou da sexualidade. Em outros contos, embora essa expressão não apareça explicitamente, percebo o processo de passagem de um não saber para um saber nos protagonistas.

O Dicionário de Semiótica entende a dimensão do saber como:

uma estrutura transitiva: é sempre o saber sobre alguma coisa, pois é inconcebível o saber sem o objeto do saber. [...] Por outro lado, o saber apresenta-se igualmente como um objeto em circulação: falar-se-á, pois, da produção, da aquisição do saber, de sua presença e de sua ausência (o não saber), e, mesmo, de seus graus. (2008, p.425).

No presente estudo, trato da passagem da dimensão da ausência para a presença, pela aquisição do objeto saber.

O enredo de "Nízia Figueira, sua criada" pode ser assim resumido: Nízia Figueira e sua criada Rufina moram em uma chácara que, mais tarde, viria a ser o bairro da Lapa. Ambas levam uma vida tranquila: Nízia trabalha em casa e Rufina vende na rua o que a patroa produz. Tudo isso sem grandes sobressaltos. Rufina engravida de um cafajeste e Nízia, em sua inocência, pensa que é doença, que ela tinha contraído antraz, que vitimara seu pai Figueira quando se mudaram de Pinda para São Paulo. Rufina dá a luz e abandona o recém-nascido. Passado esse episódio, Nízia, ao querer ser notada por algum homem, recebe a visita de seu Lemos, empregado público que a pede em casamento logo na primeira visita, o que ela aceita de imediato. Lemos começa a visitá-la, mas, depois de algum tempo, as visitas começam a se escassear e Nízia sente a falta do pretendente. Após o cessamento total das visitas de Lemos, Nízia começa a se embriagar, tal como Rufina fazia, para suportar as dores da vida. E o conto encerra numa cena em que ambas estão embriagadas, praticamente abraçadas, e com o final surpreendente: "Nízia era muito feliz".

Se o final do conto perturba o leitor dos outros contos dessa coletânea, o início também apresenta outro elemento perturbador, mas que, na minha leitura, revela ser a chave interpretativa do conto. N'Os contos de Belazarte, 
o narrador inominado introduz a narrativa com a fórmula em itálico Belazarte me contou. Após essa fórmula, temos o discurso de Belazarte, relatando um de seus "causos". Em "Nízia Figueira, sua criada", o conto inicia-se com a referida fórmula, mas o que segue é uma discussão de duas pessoas, uma das quais é o próprio Belazarte: "Pois eu acho que tem. Você já sabe que sou cristão... Essas coisas de felicidade e infelicidade não têm significado nenhum, si a gente se compara consigo mesmo". (s/d., p.103). O narrador inominado teria reproduzido trecho de uma possível discussão de Belazarte com alguém sobre o conceito de felicidade e infelicidade? Acredito que sim. E justamente pelo fato de julgar "Nízia Figueira, sua criada" como o conto-chave para entendermos esses conceitos propostos por Mário de Andrade em vários de seus textos ficcionais e poéticos, creio que a discussão entre esse "alguém inominado" e Belazarte levaria ao mote do conto: provar que felicidade e infelicidade se definem por relação.

Tal como na teoria de Saussure e na de Greimas, em que o sentido se dá por relação, Mário de Andrade parece compactuar com esse critério relacional presente nos estudos da linguagem, ao fazer o discurso de Belazarte se sobrepor ao do "alguém inominado", que se diz cristão e que, portanto, aceitaria verdades irrefutáveis, dogmas de fé sem questioná-los. Ao dizer que não há sentido para felicidade e infelicidade se nos comparamos com nós mesmos, Belazarte aponta o movimento do uno para o duplo ou para o múltiplo, caminho percorrido pelas demais personagens de Mário de Andrade. Temos, então, o que chamarei de discurso do uno e discurso do duplo e Belazarte partilhará desse último ao dizer "Infelicidade é fenômeno de relação, só mesmo a gente olhando pro vizinho é que diz o "atendite et videte". (idem, p.103). Num leve tom de ironia ao discurso do uno, Belazarte cita o ditado popular "Macaco, olhe seu rabo!" e o define como "o cruzamento da filosofia cristã com a precisão da felicidade neste mundo duro".

Ora, não há "precisão de felicidade" se considerarmos que um determinado conceito se estabelece pelo critério relacional. No entender de Freud, há, dentro da doutrina cristã, a ilusão da felicidade, que pode ser obtida pela própria religião. Essa explicação pode ser encontrada em dois de seus ensaios, intitulados "O futuro de uma ilusão" e "O mal-estar da civilização". Neste último, o autor recupera algumas das ideias do ensaio anterior, relacionando a religião como uma maneira de colocar o ego a salvo das ameaças do mundo exterior (1978, p.138). Freud evidencia o entendimento que o ser humano tem de religião como: 
[...] o sistema de doutrinas e promessas que, por um lado, lhe explicam os enigmas deste mundo com perfeição invejável, e que, por outro, lhe garantem que uma Providência cuidadosa velará por sua vida e o compensará, numa existência futura, de quaisquer frustrações que tenha experimentado aqui. O homem comum só pode imaginar essa Providência sob a figura de um pai ilimitadamente engrandecido. (1978, p.139).

Dessa forma, a religião é entendida como um dos elementos paliativos para que o indivíduo possa suportar o real, sendo, portanto, uma ilusão, algo "tão estranho à realidade" (1978, p.139). No discurso inicial de Belazarte em "Nízia Figueira, sua criada", a ilusão aparece no seguinte fragmento: "Inda é bom quando a gente inventa a ilusão da vaidade, e, em vez de falar que é mais desinfeliz, fala que é mais feliz... Toquei em rabo, e estou lembrando o caso do elefante, você sabe?" (s/d., p.103) Assim, a teoria da ilusão é comprovada por meio de uma micronarrativa encaixada na macronarrativa, na história de Nízia. Trata-se da fábula do elefante que amarrou uma penuginha de beija-flor em seu rabo e julgou ser um beija-flor. Quando uma "elefanta mocetona" resolve acasalar com ele, este responde: "Dobre a língua, sabe! Elefante não senhora! Sou beija-flor" (idem, p.103) O elefante vai embora e a fábula termina com um comentário um tanto irônico de Belazarte: "Eis aí um tipo que ao menos soube criar felicidade com uma ilusão sarapintada. É ridículo, é, mas que diabo! Nem toda a gente consegue a grandeza de se tomar como referência de si mesmo". (idem, p.103)

Essa "referência de si mesmo" aponta para a problemática da pretensa unidade buscada pelo sujeito, que se opõe à realidade duplicada em que este se encontra. De acordo com Clément Rosset, o duplo se relaciona aos mecanismos de ilusão, em que há uma recusa do real e a busca de outra realidade: "Quanto ao real, se ele insiste e teima em ser percebido, sempre poderá se mostrar em outro lugar" (1998, p.11). Segundo o filósofo, quando não suportamos algo do mundo real, nossa consciência, para nos colocar a salvo de qualquer situação indesejável, desloca o real para um outro lugar (1998, p.11), criando um duplo. A ilusão teria a mesma estrutura paradoxal do duplo, pois este implica em ser, ao mesmo tempo, uma coisa e outra.

O elefante recusa a presença do outro para manter-se em sua aparente unidade e, para isso, cria um mecanismo de ilusão: "sou beija-flor". Se fosse elefante, seria obrigado a interagir com o outro, no caso, a "elefanta mocetona". Como não quer admitir o real (ser elefante), esse real se mostra em outro lugar, 
isto é, no universo onírico do beija-flor. A tolerância com o real é suspensa, o que explicaria a resposta dada à elefanta. Não querer admitir o real faz esse elefante criar a "ilusão de vaidade" ou ainda "ilusão de felicidade", pois não se relaciona com o outro, mas se torna "referência de si mesmo".

Tal como o elefante, Nízia também se encontrava na situação de unidade, de ser referência de si mesma. Tanto que após a narração da fábula do elefante e o comentário irônico sobre a pretensa unidade buscada pelo elefante, o narrador afirma que o conceito de ilusão de felicidade só ocorreria com Nízia: "Quanto a que lhe suceda como com a Nízia, homem! Isso estou imaginando que só com ela mesmo... Que Nízia?” (s/d., p.103) E é a partir daí, como num processo de rememoração, de certezas e incertezas, que o narrador conta a esse narratário ("você sabe?") a história de Nízia, desde sua pré-história, isto é, a história do velho Figueira, que comprara um sítio no "hoje bairro da Lapa", mas que "nem bem mudou, deu com o rabo na cerca, por causa dum antraz que o panema dum boticário novato imaginou que era furúnculo" (idem, p.104).

Após a morte do velho Figueira, Nízia, que até então tinha sido "guardada com olho de Figueira pai sempre em casa" (idem, p.104), continua na companhia da criada Rufina. A relação dessa personagem com Nízia, segundo Alfredo Bosi, é marcada por uma intimidade assimétrica. Dito de outra forma, embora Nízia seja a patroa, trata Rufina de "prima" e se aproxima dela nos momentos em que ambas buscam esquecer as suas dores. No seu estudo, Bosi assim se posiciona sobre essa "intimidade assimétrica":

Nízia é patroa, Rufina é sua agregada. Nízia é branca, Rufina é negra. Nízia chama Rufina de você, mas Rufina sempre lhe dirá vossuncê ou mecê. Nízia é adolescente, Rufina tinha vinte "e muitos" [...]. Mas o que a classe e a cor separam, o sentimento pode juntar. O corpo reclama um regime de suplência que o desempenho dos papéis sociais tende a proibir e recalcar [...]. E aí temos corpo e sociedade ora unidos, ora apartados, no balé brasileiro da intimidade assimétrica. (BOSI, 1996, s/p).

Esse conceito de Alfredo Bosi de "intimidade assimétrica" também é referido no seguinte posicionamento do autor: "A história de Nízia e Rufina lembra uma dança dramática feita de distância e proximidade" (BOSI, 1996, $\mathrm{s} / \mathrm{p}$ ). Ambas as personagens apresentam, além das diferenças de classe social, diferentes atitudes e experiências (ou não experiências). 
Na passagem do não saber para o saber, importante categoria para o estudo das personagens dos contos de Mário de Andrade, é possível afirmar que Rufina passa para a modalidade do saber, enquanto Nízia permanece na apatia e na inércia. O discurso de Belazarte, ao se referir a Rufina, ganha dimensões irônicas: "Prima Rufina é que aprendeu a vida... Não contava nada, quieta, preparando a janta, cachimbo no beiço grosso. No entanto bem que aprendeu..." (s/d., p.105). Essas duas recorrências da palavra "aprendeu" antecipam a narração do envolvimento da criada com um "canhambora safado que vivia ali mesmo, nas barbas da cidade", e que fugiu com dinheiro de Rufina e a deixou grávida. Após ter o filho e abandoná-lo recém-nascido, Rufina passa a se envolver com outros homens, mas adquirira o saber necessário para evitar gravidez e perda de dinheiro: "Prima Rufina ficou doente uns dias. Depois sarou e aprendeu. Quando tinha vontade, ia nas vendas procurando homem disposto. Porém não sei como fazia, sei que nunca mais teve antraz". (idem, p.106).

Novamente, há a oposição entre saber e não saber. O narrador, que em muitos momentos do conto apresenta determinada onisciência neutra ou até mesmo intrusa, por fazer vários comentários e dialogar com o narratário, oscila entre o saber e o não saber, pois apresenta uma visão um pouco limitada, resgatada de sua memória, ao contar ao narratário o "causo" de Nízia. Ao dizer "não sei como fazia, sei que nunca mais teve antraz", o narrador dispõe sua focalização em Nízia, pois esta pensara que a gravidez da criada era um antraz, a mesma doença que vitimara o velho Figueira. A visão de Nízia é limitada. Nízia não está conjunta com a modalidade do saber e se o narrador opta por dispor da focalização narrativa sobre a personagem que dá o título ao conto, obviamente, a visão desse narrador deverá acompanhar a de Nízia.

Se por um lado o narrador oscila entre o saber e o não saber, Nízia está conjunta com este último. Segundo Raquel Illescas Bueno, as personagens Rosa e Carmela, dos contos "O besouro e a Rosa" e "Jaburu malandro", são marcadas por expressões relativas ao isolamento e a uma vida em redoma. Em "Nízia Figueira, sua criada", há as expressões "apartada", "anos de mocidade guardada", "só" e "esquecida", categorizadas pela autora como parte do campo semântico do isolamento.

Mais que "sequestrada", ou "separada", o vocábulo "esquecida" reforça a ideia de solidão extrema. Para narrar uma experiência frustrante, em que a presença de Nízia é ignorada pelos vendedores de uma loja de tecidos, o narrador emprega o sumário (ou cena sumariada), repetindo 
três vezes seguidas o verbo "esquecer" [...]. A cena ocorrida na loja é a única, no enredo, que ilustra alguma tentativa de rompimento da imobilidade. (BUENO, 1992, p.93).

Apesar de o seu isolamento persistir até o final do conto, Nízia procura insistentemente um homem, tal como a elefanta da narrativa encaixada, que "já estava carecendo de senhor pra cumprir seu destino" (s/d, p.103). No entanto, a busca pelo outro se dá de outra forma: ela busca um outro desconhecido, uma possível figura masculina, cuja estrutura ainda não conhecia: "Desejos, não posso dizer que não tivesse desejos, teve. Olhava os homens passando, alguns eram bem simpáticos, havia de ser bom com eles" (idem, p.106). A expressão "havia de ser bom com eles" indica uma hipótese, não uma certeza, indica uma possibilidade de encontro com o outro, que não é realizada na cena da loja de tecidos: "Ela ficou ali muito serena, esperando". (idem, p.106).

No entanto, após muita espera, Nízia encontra o elemento desarranjador: "Teve um momento em que a humanidade pareceu se lembrar dessa apartada, foi com seu Lemos o caso" (idem, p.107). Personagem desfibrado, seu Lemos pode ser visto como o duplo desconhecido de Nízia, a figura masculina que a completaria, na construção de uma possível identidade feminina, isto é, da passagem da infância para a adolescência, já que vivera "sequestrada" ou ainda "apartada" da vida. Esse outro que entra na história é assim descrito por Alfredo Bosi: "Nízia encorpa, vira moça, pressente o outro, que afinal chega fardado de carteiro". (BOSI, 1996, s/p). O pressentir o outro se dá de forma especular, pelo efeito de espelho, pois Nízia busca sair da inércia pelo outro. Vale lembrar que ela depende do outro: depende de Rufina e agora passa a depender de Lemos para atingir seu processo de autoconhecimento.

Elemento perturbador, seu Lemos é focalizado disforicamente no discurso do narrador e nas falas de Rufina. O narrador o caracteriza como "meio pálido", "com bigodinho torcido e cabelo crespo repartido do lado", "corpo baixote", "filho bom ele não era não". Bosi o define como "um pobre-diabo, mísero empregadinho público do Brasil cartorial-republicano, um nada sem os favores do pistolão graúdo". (BOSI, 1996, s/p).

No percurso narrativo de Lemos, percebemos que ele quer se casar com Nízia para compensar a ausência da mãe, que cuidava dos afazeres domésticos enquanto ele ia trabalhar como carteiro. Devido às rápidas mudanças de cargo (carteiro, funcionário da Secretaria do Tesouro e empregado de uma loja de 
tecidos), as visitas de Lemos ficam cada vez mais escassas. A última troca de profissão e o "pensamento por decretos" fazem com que ele assuma outras prioridades que não a de visitar Nízia. Tais prioridades são desmascaradas pelo narrador com um discurso um tanto irônico:

O coitado não queria riqueza, queria era sossego... Arranjou ùa mulata gorda pra cozinhar, dormiu uma noite no quarto da Sebastiana e depois todas as noites a Sebastiana no quarto dele, que era mais espaçoso. Sebastiana cozinhava, porém não era cozinheira mais: dona-de-casa, sempre querendo chinela nova no pé cor-de-sapota. (s/d, p.114).

Encontramos na figura de Lemos a tematização do funcionalismo público do final do século XIX, que opta por uma vida tranquila em detrimento do trabalho em excesso. Sobre Os contos de Belazarte, Raquel Bueno afirma: "Seu Lemos é a única personagem que pode ser aproximada dos 'pobres-diabos"”. (1992, p.65). Essa afirmação é corroborada por Mário de Andrade, no artigo "A elegia de abril”, em que descreve a psicologia do fracassado na literatura brasileira a partir dos anos de 1930 .

Mas em nossa literatura de ficção, romance ou conto, o que está aparecendo com abundância não é este fracasso derivado de duas forças em luta, mas a descrição do ser sem força nenhuma, do indivíduo desfibrado, incompetente pra viver, e que não consegue opor elemento pessoal nenhum, nenhum traço de caráter, nenhum músculo como nenhum ideal, contra a vida ambiente. Antes, se entrega à sua conformista insolubilidade. (ANDRADE, 2002, p.212-3).

Com a morte da mãe de Lemos, o narrador opera, de forma irônica, o primeiro desmascaramento da personagem, revelando as reais intenções dele com Nízia: "quando a mãe morreu de repente, o que sentiu foi o vazio inquieto de quem nunca lidara com pensão nem lavadeira" (s/d, p.108). Esse estado de falta, representado pela palavra "vazio" faz com que ele se interesse por Nízia, como se percebe pela focalização do narrador em relação aos pensamentos de Lemos:

Quando palitou de novo a barulhada dos sapos nessa noite, seu Lemos começou a pensar que ali estava uma moça boa pra casar com ele. Não refletiu, não comparou, não julgou, não resolveu nem nada, seu Lemos pensava por decretos espaçados. Pois um decreto apareceu em letras vagarentas no bestunto dele: Ali está uma moça boa pra casar com você. 
Na palitação do dia seguinte, estava escrito na cabeça dele: Você vai casar com a moça do portão. (idem, p.108).

Mais do que no discurso do narrador, é no discurso de Rufina que percebemos que Lemos representa um "desarranjo" na vida pacata de Nízia: “Tou vendo mas é que seu Lemes veio atrapaiá tudo a vida nesta casa!" (idem, p.111). Em outro momento, Rufina, ainda que com uma visão simplória, realiza outro julgamento disfórico em relação a seu Lemos: "Essa história di sê empregado no Correio, num me parece que seja coisa dereita não, infim..." (idem, p.111). Sobre o fato de Nízia ter aceitado se casar com ele, Rufina assim se posiciona: "Mecê carece dum home nesta casa que lhe proteja mas porém ansim! Premero que aparece, vai ficando noiva! Nem num sabe si seu Lemos quem é, arre credo! Será que anda bem com os puliça!” (idem, p.111).

Apesar da disforia presente no discurso do narrador e no de Rufina, Nízia vê Lemos com euforia. Na leitura que faço de "Nízia Figueira, sua criada", Lemos representaria um duplo imortal para Nízia, não entendido aqui como um desdobramento de personalidade, mas como o lugar desconhecido para Nízia, importante para garantir sua existência. Clément Rosset, ao citar o estudo de Otto Rank sobre o referido fenômeno, discorda em partes da afirmação do psicanalista sobre o fato de o desdobramento da personalidade estar relacionado com o medo ancestral da morte.

É verdade que o duplo é sempre intuitivamente compreendido como tendo uma realidade "melhor" do que a do próprio sujeito - e ele pode aparecer neste sentido como representando uma espécie de instância imortal em relação à mortalidade do sujeito. Mas o que angustia $o$ sujeito, muito mais do que a sua morte próxima, é antes de tudo a sua não realidade, a sua não existência. Morrer seria um mal menor se pudéssemos ter como certo que ao menos se viveu. (ROSSET, 1998, p.78).

Na cena em que Nízia vai à "loja concorrida da cidade", ela quer ser vista. Em determinado momento, o narrador diz que ela "principiou se enfeitando, foi na cidade algumas vezes" (s/d, p.106). Nízia quer passar do estado simbólico de morte, da sua "não realidade", ou ainda, da sua "não existência", para o estado de vida, que se daria no encontro com o outro, esse duplo imortal, que pelo menos operaria a passagem do estágio de morte simbólica para o estágio de vida na personagem Nízia. Depois do insucesso da ida de Nízia à loja da cidade, o duplo, aquele que garantiria sua existência 
como ser social, passa a ser representado por Lemos, que pede a mão de Nízia em casamento sem conhecê-la muito bem: "Ele falou que vinha pedir a mão dela em casamento, ela respondeu que estava bom" (idem, p.109). Como num espelho, o pensamento por decretos de seu Lemos, figurativização do universo do não pensar ou do maquinismo do pensamento, encontra na resposta positiva de Nízia um espelho do não saber. Dito de outra forma, Lemos é o próprio espelho de Nízia, pois ambos possuem uma existência inautêntica, ele pensa por decretos, ela vive na inércia e na apatia, é a apartada do mundo social.

No que concerne à temporalização do conto a partir da entrada de Lemos no universo de Nízia, encontramos o tempo extenso e o tempo intenso. Ao ficar noivo de Nízia, seu Lemos passa a adiar suas visitas à casa da noiva. Luiz Tatit, ao investigar o ritmo da canção, estabelece novas categorias de sentido a partir dos estudos da chamada "Semiótica Tensiva" e propõe uma articulação dos conceitos de tensão e relaxamento, fundamentais para entendermos as relações de alteridade entre as personagens dos contos em análise. As categorias de "intensidade" e "extensidade" são analisadas pela semiótica tensiva, em modelo proposto por Fontanille e Zilberberg, e adaptado por Luiz Tatit.

Para Tatit, "a semiótica de hoje considera que qualquer evento na cadeia discursiva pode ser enfocado como um ponto tensivo em que colidem forças antagônicas representadas pelas categorias (ou valências) intensidade /vs/ extensidade". (2001, p.121). Para o semioticista, as paixões humanas podem ser apresentadas nos textos ora inclinando-se para a intensidade ora para a extensidade. Conforme Tatit, na articulação entre a temporalização do texto e seus aspectos tensivos, pode-se afirmar que enquanto a intensidade pressupõe apressamento do tempo ou antecipação de algo, a extensidade propõe o adiamento do tempo ou o retardar de algo (2001, p.119-27).

Ao adiar as visitas à casa da noiva e vivenciar o noivado de forma extensa, Lemos deixa Nízia em um estado de "deslumbramento simultâneo de felicidade e amargura" (s/d, p.112), pois a moça passa a viver o tempo de forma intensa, esperando constantemente a visita do noivo. Tal como a estrutura do duplo (paradoxal em sua conceituação), há o paradoxo na simultaneidade de amargura e felicidade, sendo esta última o grau zero de dor, a existência inautêntica, a total apatia ou ainda a morte simbólica do sujeito. Para Freud, a felicidade, no seu sentido mais restrito, "provém da satisfação (de preferência repentina) de necessidades represadas em alto grau, sendo, por sua natureza, possível apenas como uma manifestação episódica" (1978, p.141, grifos meus). 
Por outro lado, a infelicidade estaria relacionada à amargura, resultado da passagem do não saber para o saber, do estado de morte para o estado de vida, da existência inautêntica para a existência autêntica. Segundo o referido psicanalista, a infelicidade é mais comum de se experimentar do que a felicidade (esta última episódica) e resulta de sofrimentos provenientes de três direções: do nosso corpo em seu envelhecimento e dissolução, do mundo exterior que pode nos esmagar, e dos nossos relacionamentos com outros seres humanos, entendido este último como o "mais penoso do que qualquer outro". (1978, p.141).

Estar espelhada no seu objeto amoroso faz com que Nízia deseje estar com Lemos a todo momento. Como isso não é possível devido às visitas espaçadas do carteiro, Nízia passa do estado de "felicidade", ou melhor, "ilusão de felicidade", para o estado de "amargura", resultado do sofrimento provocado por outro ser humano, no caso Lemos:

A felicidade de Nízia fizera dela uma desgraçada. Do passado e esquecimento de dantes não se lembrava, mas agora é que fazia ela sofrer. Noivo, seu Lemos achou que não carecia mais de passar todo santo dia pela casa da noiva, tarde veio e seu Lemos não veio (s/d, p.111-2).

Dessa forma, Nízia vive a espera do noivo de forma intensa, pois a ausência do mesmo gera a falta causadora de angústias na personagem. Parece repetir para si mesma "Vem amanhã", como forma de mascaramento do real, isto é, de maneira a fazer a si mesma crer na iminência de um retorno de Lemos: "De repente ficara desgraçada. "Vem amanhã", murmurejou sofrendo de prazer. E repetiu "Vem amanhã" até na quinta-feira" (idem, p.112). Novamente, encontra-se o apogeu simultâneo de felicidade e amargura, representado na estrutura paradoxal de "sofrendo de prazer".

A visita de Lemos ocorre, pois, na quinta-feira, bem rápida, das seis da tarde às oito da noite, marcada pelo maquinismo dos diálogos, isto é, "aquelas frases de companheiro que não esperam resposta, só pra reconhecimento de existência junta" e pelo presente ofertado à noiva, um "brochinho de ouro escrito LEMBRANÇA" (idem, p.112). No final da visita, seu Lemos promete casamento e afirma retornar no domingo, volta apenas realizada na terça, com Nízia "feliz duma vez" ao dar um cachenê ao noivo. Esse estado de felicidade - ou melhor, de ilusão de felicidade, como é possível analisar pela proposta de Rosset -, relaciona-se ao sofrimento, como se observa explicitamente no seguinte fragmento: 
Entre inércia e apatia: tensões e relaxamentos em Nízia Figueira, sua criada...

Nízia tricotando sem saber. A luz do lampeão mariposava em volta da cabeça dela e, no calor seco da sala, as palavras de seu Lemos se pronunciavam ainda, sonorosas de verdade, como afago doce de companheiro. Nízia sofreu que você nem imagina. Sofreu aquele sapatinho de lã; sofreu por causa de prima Rufina que estava envelhecendo muito depressa; sofreu aqueles vestidos de cassa eternamente os mesmos, carecia fazer outros; as toalhinhas de crochê não ficaram bem lavadas; ela era um poucadinho mais gorda que seu Lemos. (idem, p.113).

Conforme este fragmento, Nízia passa a ter medo do tempo acelerado, responsável pelos sofrimentos (quatro recorrências do verbo sofrer) advindos das três direções apontadas por Freud: de outro ser humano (no caso Lemos, como elemento desarranjador), do envelhecimento do próprio corpo (e aqui entraria também o envelhecimento de Rufina como alter ego de Nízia) e do mundo exterior marcado pela mesmice. Sobre o mundo exterior, o fragmento parece demonstrar certa percepção de Nízia (ainda em estágio embrionário) de que ela vivia numa existência inautêntica, figurativizada pelos vestidos de cassa sempre iguais, pelo sapatinho de lã, pelas toalhinhas de crochê que não estavam bem lavadas, tematização do percurso do cosmos, da inércia e da apatia da personagem, presentes no momento anterior ao aparecimento de Lemos.

Tanto o discurso do narrador como o de Rufina apontam em Lemos o elemento desarranjador desse universo cosmogônico de Nízia, pois agora "carecia fazer outros" vestidos, como carecia muita coisa no universo caótico dessa personagem, instaurado após a entrada de Lemos em sua casa. Do ato de tricotar sem saber, revelador da esfera cosmogônica e da morte pré-social de que nos fala Bosi, Nízia passa para o percurso caótico (marcado por muito sofrimento), em que as necessidades de superar as faltas se figurativizam em todo esse fragmento, e ganham intensidade que vão desde o desejo de comprar novos vestidos e ficar mais magra para agradar ao noivo, até o medo do envelhecimento de Rufina.

Ora, se Nízia projeta no outro a realização de seus desejos, a ausência de Lemos é sentida com tanto sofrimento como a possibilidade da perda de Rufina. Vale lembrar que quando Rufina tivera o filho, que em seguida abandonara, ao pensar que a gravidez da criada fosse um antraz - doença que causara a morte do velho Figueira -, Nízia repete a estrutura básica da morte do duplo: se o duplo morre, o original também morre, uma vez que o duplo é o original que ele próprio duplica. Sobre essa estrutura, Rosset cita o conto 
"William Wilson", de Edgar Allan Poe, "quando o único (aparentemente o duplo de Wilson) sucumbiu aos golpes de seu duplo (que é o próprio narrador)" (ROSSET, 1998, p.78).

Diferente do narrador do conto de Poe, Nízia não quer a destruição do duplo. Pelo contrário, ela quer assegurar a sua vida no outro, que pode ser tanto Rufina como Lemos. O narrador assim resume a aflição de Nízia na cena em que esta pensa que Rufina poderia morrer de antraz: "Nízia teve mortes, do medo de ficar sozinha". (s/d, p.105). Se morresse Rufina, o duplo de Nízia, esta passaria novamente ao estado de morte, ao estado de pureza, entendida como o estado do uno em oposição à impureza, estado do múltiplo, representado pela percepção do outro. Perceber as dores de Rufina, ainda que de forma um tanto inocente, mostra um início de uma entrada no mundo adulto, em que a categoria da alteridade se faz presente.

De modo análogo, o retardamento das visitas de Lemos causa em Nízia um estado de tensão. Nas modalidades tensivas propostas por Zilberberg, tensão estaria ligada à disjunção do sujeito do seu objeto-valor, enquanto relaxamento, à conjunção com o objeto Esse modelo proposto pelo semioticista encontra correlações na psicanálise freudiana, conforme estabelecido por Diana Luz Pessoa de Barros. Para a autora, "A tensividade, para Zilberberg, é uma propriedade do ser vivo ou, mais exatamente, do encontro do ser vivo com o não-vivo, concepção que lhe permite homologar a forja ao princípio do prazer de Freud, à pulsão" (1988, p.26). Dessa forma, a pulsão de vida, da teoria de Freud, corresponde à tensão, da teoria de Zilberberg, enquanto a pulsão de morte, ao relaxamento.

No nível narrativo do conto em análise, Nízia encontrava-se em estado de relaxamento, no espaço cosmogônico, marcado pela rotina de seus afazeres e pela apatia com que se encontrava diante das relações com o mundo social. Com a entrada de Lemos e a possibilidade de ser percebida pelo outro, Nízia passa a um estado de tensão, vivendo dois tipos de relação: extensa, figurativizada pelo retardamento das visitas de Lemos, e intensa, configurada pelas angústias sentidas pela personagem.

Todas essas infelicidades que nunca sentira, e que doem tanto pra quem não pode ter outras: era a voz de seu Lemos que trazia, pondo como espelho diante dela, o corpo do companheiro. Foi pro quarto e pela primeira vez depois do antraz da preta, não dormiu logo. Pensar não pensou, era também dos gêneros dos decretos. Como decreto não 
Entre inércia e apatia: tensões e relaxamentos em Nízia Figueira, sua criada...

vinha, ficou espalhada na escuridão, sentindo apenas que vivia, feliz, encostada na vida do companheiro. (s/d, p.107).

Nesse fragmento, além do estado de tensão causado pelo distanciamento de Lemos, encontra-se o efeito espelho, isto é, Nízia permanece no estado de existência inautêntica ("ficou espalhada na escuridão, sentindo apenas que vivia"), dependendo de Lemos para existir enquanto sujeito ("encostada na vida do companheiro"). Conforme o discurso de Clément Rosset, se o duplo representa uma realidade superior à realidade do sujeito, este real-aqui é posto em outro lugar, na estrutura paradoxal do duplo (ser ela mesma e outra). Dito de outra forma, a realidade cotidiana de Nízia, marcada pelo seu confinamento, pela inércia e apatia parece ser colocada em outro lugar, desdobrando assim duas realidades: a existência cosmogônica em oposição à existência caótica. Por mais que o caos possa parecer disfórico, é nele, é nessa realidade duplicada que Nízia passa a construir sentidos, pois pensa como Lemos ("era também dos gêneros dos decretos"), e busca construir sua identidade no espelhamento com o outro ("pondo como espelho diante dela, o corpo do companheiro").

Como proposto anteriormente, esse duplo que assegura a existência de Nízia pode ser tanto Lemos como Rufina, pois na cena final do conto, em que ambas estão embriagadas, pode-se perceber, seguindo o ensaio de Alfredo Bosi, o baile dessa intimidade assimétrica, a passagem da assimetria social para a intimidade. É na pinga onde se dá o encontro entre duas solidões, entre as frustrações com a vida, de forma que Nízia e Rufina se enlaçam no abraço de duas condenadas ao fracasso da vida.

Se fracassa a vida, estado de tensões, a medida paliativa é seguramente o álcool, que daria a ilusão de felicidade, tal como ocorre com o elefante da micronarrativa encaixada e conforme o posicionamento crítico de Mário de Andrade, em prefácio abandonado para a primeira edição de Belazarte: "Belazarte é um bom começo. Tem a piedade dos seres reais, que não tenho. E sabe conceber o que seja a felicidade. Quando a busca não acha ou a supõe nos bêbados. É uma limitação amarga e insuportável”. (2008, p.150).

Além de enfatizar a piedade como marca predominante do narrador Belazarte, o autor estabelece um paralelo entre a ilusão de felicidade e a bebida. O uso imoderado do álcool apresenta os mesmos efeitos das substâncias tóxicas estudadas por Sigmund Freud como uma das três medidas paliativas para suportar as desgraças e os sofrimentos. Para o psicanalista, as substâncias 
tóxicas, quando presentes no nosso corpo, "provocam em nós, diretamente, sensações prazerosas, alterando, também, tanto as condições que dirigem nossa sensibilidade, que nos tornamos incapazes de receber impulsos desagradáveis". (1978, p.142).

De forma correlata à formulação freudiana dos tóxicos, o uso excessivo do álcool é entendido por Clément Rosset como um mecanismo de "cegueira voluntária":

Posso, enfim, sem sacrificar nada da minha vida nem de minha lucidez, decidir não ver um real do qual, sob um outro ponto de vista, reconheço a existência: atitude de cegueira voluntária, que simboliza o gesto de Édipo furando os olhos, no final de Édipo Rei, e que encontra aplicações mais ordinárias no uso imoderado do álcool ou da droga. (1998, p.13).

Por não suportar o real (incesto com a mãe Jocasta), Édipo fura os olhos. Não ver mais o real, é o que deseja a personagem central da tragédia de Sófocles. Por se perceber disjunta da felicidade ("vivia, feliz, encostada na vida do companheiro"), Nízia cria outra ilusão de felicidade: ao invés de se encostar na "vida do companheiro", passa a se encostar na vida de Rufina, nesse balé de intimidade assimétrica. Diz Alfredo Bosi: "Nízia e prima Rufina se irmanam na bebida. A assimetria parece desmanchar-se e dissolver-se nos enormes pifões noturnos em que as duas mulheres, a patroa branca e a criada preta, se escoram uma na outra antes de caírem emboladas no chão" (BOSI, 1996, s/p). Esse escoramento de uma na outra, tal como um espelho de frustrações, pode ser visto no seguinte fragmento:

Nízia piscava olhos secos, embaçados, entredormindo. Escorregava. Ia babar num beijo mole sobre o pezão de prima Rufina. Esta queria passar a mão na outra pra consolar, vinha até a borda da cama e caía sobre Nízia, as duas se misturando num corpo só. (s/d, p.116).

Novamente recorro a Bosi: "Mas o que a classe e a cor separam, o sentimento pode juntar" (1996, s/p). Nesse estado de embriaguez, em que Nízia e Rufina estavam "se misturando num corpo só", o espelhamento atinge uma determinada intensidade que faz com que Rufina também sofra o processo de duplicação. Ao ressaltar várias vezes que a bebida faria Nízia esquecer os problemas do mundo, Rufina afirma que o "pifão" faria Nízia esquecer do filho que tivera. Aí surge um estranhamento para o leitor: em nenhum momento, o narrador inominado conta ou sugere que Nízia tivera um filho. Sabe-se que foi 
Rufina quem engravidara de um "canhambora", que "botara o desgraçadinho pra fora" e que abandonara o recém-nascido. No entanto, ambas estão tão fundidas pela bebida, que faz com que Rufina duplique o real, deslocando os acontecimentos disfóricos de sua vida para outro lugar. Para Freud, em estados patológicos, é comum as linhas fronteiriças entre o ego e o mundo exterior se tornarem incertas $(1978$, p.133). Segundo o psicanalista:

Há casos em que partes do corpo de uma pessoa, inclusive partes de sua própria vida mental - suas percepções, pensamentos e sentimentos -, lhe parecem estranhas e como não pertencentes a seu ego; há outros casos em que a pessoa atribui ao mundo externo coisas que claramente se originam em seu próprio ego e que por este deveriam ser reconhecidas. (1978, p.133).

O lugar para onde Rufina desloca os eventos disfóricos de sua vida é o corpo de Nízia, o qual pode ser entendido, na leitura freudiana, como o mundo externo daquela. $\mathrm{O}$ trauma do nascimento do filho indesejado deixara fortes marcas em Rufina, que, não conseguindo lidar com esse conflito, projeta-o, no estado de embriaguez, para outro corpo, que é, portanto, externo a seu ego. Nessa confusão entre ego e mundo externo, em que ambas se tornam praticamente um só corpo, Nízia recebe as seguintes palavras de Rufina no estado de embriaguez em que ambas se encontravam:

- É isso memo, mia fia... num chore mais não! A gente toma pifão dá gosto e bota disgraça pra fora... Mecê pensa que pifão num é bom... é bão sim! Pifão... pifãozinho... pra esquenta desgraça desse mundo duro... O fio de mecê, num sei que-dele ele não. Fio de mecê deve de andá pur aí, rapaiz, dicerto home feito...dicerto mecê já isbarrô cum ele, mecê num conheceu seu fio, seu fio num cunheceu mecê... Num chore mais ansim não!... Pifão faiz mecê esquecê seu fio, pifão... pifão... pifãozinho... (s/d, p.116)

Alfredo Bosi ressalta que, apesar dessa intimidade, ainda existe uma diferença sutil entre Nízia e Rufina, pois esta última "conheceu o mundo até as entranhas". (BOSI, 1996, s/p). O crítico parece referir-se ao episódio já citado do "canhambora" que explorou Rufina, levou seu dinheiro e a deixou grávida. No trecho em que Rufina está prestes a dar à luz, aparecem algumas recorrências da bebida como mecanismo de cegueira voluntária, tal como: "Pinga já estava toda no lugar do tiziu saído e sonhando na capa de xadrez. Carecia de coragem. Pois foi na guarda-comida buscar o espírito-de-vinho e 
mamou na garrafa mesmo. Enrolou bem a criancinha e saiu, saiu sim!" (s/d, p.105). É a pinga que faz Rufina desdobrar o real e colocá-lo em outro lugar, da mesma forma que abandona a criança, fruto desse real recusado.

De fato, Rufina "conheceu o mundo até as entranhas", passou do não saber ao saber. Ela aprende a vida, como diz Belazarte: "Depois sarou e aprendeu" (idem, p.106). É essa a diferença que reside entre as duas personagens femininas do conto: Rufina passa do não saber para o saber, enquanto Nízia permanece no não saber, voltando ao estado de "inocência primeira", como propõe Bosi: "É como se a pinga doce e ardente a levasse de volta para aquela inocência primeira, anterior a todo conhecimento; estado miticamente pré-social onde enfim o narrador pode inscrever o fecho imprevisto" (BOSI, 1996, s/p).

Considerando o percurso narrativo proposto por Greimas, o sujeito Nízia realiza um programa virtual. Entende-se o saber como um dos elementos modais para a realização da ação principal do sujeito, além de determinante nos rituais de passagem das personagens dos contos de Mário de Andrade. Percebe-se, pela leitura de "Nízia Figueira, sua criada" que falta esse saber para a protagonista, de forma que a mesma não constrói sua identidade de forma plena, diferente do que ocorre com outras personagens femininas d' $O s$ contos de Belazarte. Considero necessário afirmar que não seria exatamente um retorno à "inocência primeira", mas sim uma permanência nesse estado de não saber, já que a relação de espelhamento em Lemos não chega a fazer com que Nízia fique conjunta com o saber. O efeito espelho ocorre neste conto da seguinte maneira: Nízia quer ser como o outro, quer encontrar nele mecanismos para construir sua identidade, quer ser vista, quer ser reconhecida. Mas só quer, não sabe. Falta-lhe esse elemento modal para que sua identidade seja construída.

$\mathrm{Na}$ estrutura narrativa de "Nízia Figueira, sua criada", um conflito é esboçado, qual seja, a passagem da felicidade (dimensão cognitiva do não saber) para a infelicidade (dimensão cognitiva do saber) e o regresso ao estado de inocência primeira, ou a permanência nesse estado, e às virtualidades de construção de identidade pelo outro, pelo efeito espelho. Permanência ou retorno ao "estado miticamente pré-social" proposto por Bosi, Nízia é a única personagem d'Os contos de Belazarte com "final feliz". Feliz à medida que venho analisando, uma ilusão de felicidade, tal como o elefante da micronarrativa. Tanto Nízia (personagem da narrativa encaixante) como o elefante 
(narrativa encaixada, pequeno simulacro da narrativa encaixada) acabam por se fechar em seus próprios mundos, talvez como uma das medidas paliativas de evitarem sofrimentos advindos do contato com o Outro, representado por outras personagens ou pelo espaço social/simbólico em que estão inseridos.

\section{Referências}

ANDRADE, Mário de. A elegia de abril. In: 6.ed. Belo Horizonte: Editora Itatiaia, 2002. p. 207-18.

. Aspectos da literatura brasileira. . Os contos de Belazarte. São Paulo: Círculo do Livro, s/d. p.145-150. . Prefácio inédito. In: . Os contos de Belazarte. Rio de Janeiro: Agir, 2008.

BARROS, Diana Luz Pessoa de. Teoria do discurso: fundamentos semióticos. São Paulo: Atual, 1988.

BOSI, Alfredo. Intimidade e assimetria. Jornal do Brasil, 29.06.1996.

BUENO, Raquel Illescas. Belazarte me contou: um estudo de contos de Mário Andrade. Dissertação (Mestrado). São Paulo: FFLCH-USP, 1992.

FREUD, Sigmund. O mal-estar na civilização. Trad. José Octávio de Aguiar Abreu. São Paulo: Abril Cultural, 1978. p. 129-194. (Os Pensadores).

GEBRA, Fernando de Moraes. Identidades intersubjetivas em contos de Mário de Andrade. Tese (Doutorado). Curitiba: UFPR, 2009.

GREIMAS, Algirdas Julien; COURTÉS, Joseph. Dicionário de semiótica. Trad. Alceu Dias Lima et al. São Paulo: Contexto, 2008.

ROSSET, Clément. O real e seu duplo: ensaio sobre a ilusão. Apres. e trad. José Thomaz Brum. Porto Alegre: L\&PM, 1998.

TATIT, Luiz. Análise semiótica através das letras. São Paulo: Ateliê Editorial, 2001.

Recebido para publicação em 21 de novembro de 2011.

Aceito para publicação em 20 de fevereiro de 2012. 